\title{
ADUBAÇÃO NITROGENADA EM COBERTURA NO GIRASSOL IRRIGADO NAS CONDIÇÕES DE CASSILÂNDIA-MS
}

\author{
Nitrogen side dressing fertilization in irrigated sunflower under conditions of Cassilândia-MS
}

\author{
Guilherme Augusto Biscaro', João Riquelme Machado², Mauro da Silva Tosta ${ }^{3}$, \\ Vander Mendonça ${ }^{4}$, Rogério Peres Soratto ${ }^{5}$, Laércio Alves de Carvalho ${ }^{6}$
}

\begin{abstract}
RESUMO
O nitrogênio é o nutriente mais requerido pelas plantas por assumir funções importantes no metabolismo vegetal. Na cultura do girassol, sua deficiência causa desordem nutricional, sendo o nutriente que mais limita a produção. Além disso, doses elevadas podem aumentar a incidência de pragas e doenças afetando a produção de grãos. Conduziu-se o experimento com o objetivo de avaliar a resposta da cultura do girassol (Helianthus annuus L.) irrigado, submetido a diferentes doses de nitrogênio aplicado parceladamente, em cobertura. $\mathrm{O}$ delineamento experimental utilizado foi em blocos casualizados, com quatro repetições. Os tratamentos consistiram de quatro doses de nitrogênio $\left(0,20,40\right.$ e $\left.80 \mathrm{~kg} \mathrm{ha}^{-1}\right)$, na forma de uréia. A adubação nitrogenada em cobertura proporcionou um aumento em todas as características estudadas, sendo que a dose de $\mathrm{N}$ de máxima eficiência técnica para se ter uma boa produtividade é de $55 \mathrm{~kg} \mathrm{ha}^{-1}$ de $\mathrm{N}$ para o cultivo do girassol, na região de Cassilândia-MS.
\end{abstract}

Termos para indexação: Helianthus annuus L, girassol, nutrição mineral, irrigação, produtividade.

\begin{abstract}
Nitrogen is the most required nutrient by plants for exerting important functions in the vegetable metabolism. In sunflower crop, its efficiency causes nutritional disorder, being the nutrient that most limits the yield. Besides, high doses may increase the incidence of pests and diseases, affecting the yield. Hereafter, this experiment was carried out with the aim of evaluating the response of the irrigated sunflower crop (Helianthus annuus L.) submitted to different doses of side dressing nitrogen fertilization applied uncovered nitrogen in small parts. A randomized complete block design, with four replications was used. The constituted by four doses of nitrogen $\left(0,20,40\right.$, and $\left.80 \mathrm{~kg} \mathrm{ha}^{-1}\right)$, as urea. Side dressing nitrogen fertilization provides increase in all characteristics studied, and the dose of $\mathrm{N}$ of maxim suitable technical efficiency to have a good yield is of $55 \mathrm{~kg} \mathrm{ha}^{-1}$ of $\mathrm{N}$ for the cultivation of the sunflower irrigated in the region of Cassilândia, Mato Grosso do Sul State.
\end{abstract}

Index terms: Helianthus annuus L, sunflower, mineral nutrition, irrigation, yield.

(Recebido em 28 de abril de 2006 e aprovado em 26 de março de 2007)

\section{INTRODUÇÃO}

A cultura do girassol (Helianthus annuus L.)em nosso país ainda é bastante limitada e precisa haver muita expansão para poder competir com outras culturas de ponta, o que vem acontecendo gradualmente. Na safra de 2003/04, a área destinada à oleaginosa foi somente de 55,7 mil hectares; já no ano seguinte foi de 44 mil hectares, havendo um decréscimo de $21 \%$ da área plantada. O cultivo de girassol voltado à produção de grãos concentra-se nos estados de Goiás (70\% da produção na safra 2002), Mato
Grosso do Sul (12,6\% da produção na safra 2002) e Rio Grande do Sul (8,1\% na safra 2002). Paraná e Mato Grosso juntos, foram responsáveis por aproximadamente 9,3\% da produção total em 2002 (SMIDERLE, 2004).

$\mathrm{O}$ nitrogênio desempenha importante função no metabolismo e na nutrição da cultura do girassol, e a sua deficiência causa a desordem nutricional sendo que esse nutriente é o que mais limita a sua produção, enquanto seu excesso ocasiona decréscimo na porcentagem de óleo, e doses elevadas podem aumentar a incidência de pragas e

\footnotetext{
${ }^{1}$ Engenheiro Agrícola, Doutor, Professor Adjunto - Faculdade de Ciências Agrárias/FCA - Universidade Federal da Grande Dourados/UFGD Rodovia Dourados-Itahum, Km 12 - Cx. P. 533 - 79804-970 - Dourados, MS - gbiscaro@ufgd.edu.br

${ }^{2}$ Engenheiro Agrônomo - Universidade Estadual de Mato Grosso do Sul/UEMS - Rodovia MS 306, Km 6.4 - Zona Rural - $79590-00$ - Cassilândia, MS joao_riquelme@yahoo.com.br

${ }^{3}$ Engenheiro Agrônomo - Departamento de Ciências Vegetais/DCV - Universidade Federal Rural do Semi-Árido/UFERSA - Br 110, Km 47 - Presidente Costa e Silva - 59625-900 - Mossoró, RN - maurosilvatosta@yahoo.com.br

${ }^{4}$ Engenheiro Agrônomo, Doutor, Professor Adjunto - Universidade Federal Rural do Semi-Árido/UFERSA - Br 110, Km 47 - Presidente Costa e Silva 59625-900 - Mossoró, RN - Vander@ufersa.edu.br - Bolsista de Produtividade em Pesquisa/CNPq

${ }^{5}$ Engenheiro Agrônomo, Doutor, Professor Assistente - Departamento de Produção Vegetal - Faculdade de Ciências Agronômicas/FCA - Universidade Estadual Paulista/UNESP - Rua José Barbosa de Barros, 1780 - Cx. P. 237 - 18610-307 - Botucatu, SP - soratto@fca.unesp.br

${ }^{6}$ Engenheiro Agrônomo, Doutor, Professor Adjunto - Pró-Reitoria de Pesquisa, Divisão de Pós-Graduação/PROPP - Universidade Estadual de Mato Grosso do Sul/UEMS - Cidade Universitária de Dourados - Zona Rural - Cx. P. 351 - 79804-970 - Dourados, MS - Icarvalh@uems.br
} 
doenças, afetando a produção de grãos. O parcelamento do nitrogênio é indicado, sendo $1 / 3$ na semeadura e $2 / 3$ após 30 dias em solos de textura arenosa, juntamente com aplicação de 1,0 $\mathrm{kg} \mathrm{ha}^{-1}$ de boro (SMIDERLE, 2000).

O número de aquênios por capítulo é um reflexo da ação do nitrogênio na fase crítica da diferenciação floral, que ocorre nos primeiros estágios do desenvolvimento do girassol e o número potencial de flores é determinado muito cedo e afeta o número de aquênios, por decorrência afeta também o diâmetro do capítulo (ZAGONEL \& MUNDSTOCK 1991).

O diâmetro do capítulo é uma das características morfológicas mais afetadas pela adição de nitrogênio, evidenciando aumentos mesmo com doses pequenas (25 $\mathrm{kg} \mathrm{ha}^{-1}$ de N) (SAMENI et al., 1976). Porém, esse aumento não é contínuo com o incremento do N (SFREDO et al., 1984).

Castro et al. (1999), Fleck \& Silva (1989) e Steer \& Hocking (1983) estudando efeitos e métodos de aplicação de uréia em girassol, em três anos agrícolas, observaram que houve uma diferença no peso de 1000 aquênios (g) somente para o método de incorporação com grade (parcelamento de N), conseguindo um peso médio de 38,2 g. A resposta ao nitrogênio resulta do aumento do peso médio de aquênios e aplicação mais tardia, no entanto, pode proporcionar maiores pesos de aquênios.

Segundo Zagonel \& Mundstock (1991), a altura de planta é um reflexo das condições nutricionais no período de alongamento do caule, onde verificou-se que, para cultivar Contisol 711, a época de aplicação foi mais importante para o alongamento do caule do que a quantidade de nitrogênio aplicado.

Zagonel \& Mundstock (1991), verificaram que a produção de aquênios, da cultivar Contisol 711, atingiu o máximo a $80 \mathrm{~kg} \mathrm{ha}^{-1}$ de $\mathrm{N}$, num rendimento de $2125 \mathrm{~kg} \mathrm{ha}^{-1}$ de aquênios. Em adição, Lozanovic \& Stanojevic (1988), constataram que o aumento na dose de nitrogênio afetou positivamente a produção do girassol até $90 \mathrm{~kg} \mathrm{ha}^{-1}$ de $\mathrm{N}$; adubações de 120 e $150 \mathrm{~kg} \mathrm{ha}^{-1}$ de $\mathrm{N}$ reduziu as produções em 17 e $21 \%$, respectivamente. Os autores concluíram que a ação depressiva das doses elevadas pode ser parcialmente explicada pelo subdesenvolvimento das raízes.

Carvalho \& Pissaia (2002), trabalhando com cobertura nitrogenada em girassol sob plantio direto na palha, observaram que houve um aumento do peso de 1000 aquênios na dose máxima de $125 \mathrm{~kg} \mathrm{ha}^{-1}$ de $\mathrm{N}$, alcançando 71,1g de aquênios. Zagonel \& Mundstock (1991), verificaram que o peso médio de aquênios da cultivar DK 180 respondeu a maiores quantidades de nitrogênio, na dose máxima de $120 \mathrm{~kg} \mathrm{ha}^{-1}$ de N, bem como as épocas de aplicação.

Objetivou-se, neste trabalho, avaliar a resposta da cultura do girassol irrigado submetido a diferentes doses de nitrogênio em cobertura, nas condições de Cassilândia-MS.

\section{MATERIAL E MÉTODOS}

O experimento foi desenvolvido em condições de campo, no período de março a agosto de 2005, na área de Horticultura Irrigada I ( $19^{\circ} 05^{\prime} \mathrm{S}, 51^{\circ} 56^{\prime}$ W e altitude de 471 m) da Unidade Universitária de Cassilândia (UUC), Universidade Estadual de Mato Grosso do Sul (UEMS), Cassilândia/MS. Durante a condução do experimento, a temperatura média foi de $26,7^{\circ} \mathrm{C}$, a umidade média do ar foi de $65,52 \%$ e a precipitação total no período foi de $124 \mathrm{~mm}$. Esses dados foram coletados pela estação meteorológica automatizada da UUC.

O delineamento experimental utilizado foi o de blocos casualizados, sendo testadas quatro doses de nitrogênio $\left(0,20,40\right.$ e $\left.80 \mathrm{~kg} \mathrm{ha}^{-1}\right)$, com quatro repetições. A aplicação do nitrogênio foi parcelada em três vezes e realizada aos 15, 30 e 45 dias após a emergência (DAE). Cada parcela foi constituída de quatro linhas espaçadas em 0,80 m (2,4 x 3,0 m), sendo considerada como área útil duas linhas de 3,0 metros. O solo da área experimental é um Neossolo Quartzarênico (EMBRAPA, 1999).

Antes do plantio as sementes foram tratadas com os fungicidas Captan na dosagem de $(160 \mathrm{~g}$ do i.a. $/ 100 \mathrm{~kg}$ sementes), sendo que o plantio foi realizado no dia 06/05/ 2005. O período entre a germinação e a emergência foi de aproximadamente seis dias. A adubação de base foi de 500 $\mathrm{kg} \mathrm{ha}^{-1}$ da fórmula-NPK 04-14-8, no sulco de semeadura. Foi realizada adubação com boro via foliar juntamente com os inseticidas (zetacypermethrin $25 \mathrm{~g}$ do i.a. $\mathrm{L}^{-1} \mathrm{e}$ thiamethoxan $250 \mathrm{~g}$ do i.a. $\mathrm{kg}^{-1}$ ), em cada parcelamento da adubação de cobertura. Juntamente com a segunda adubação de cobertura foram aplicados $390 \mathrm{~kg} \mathrm{ha}^{-1} \mathrm{de}$ superfosfato simples, em todos os tratamentos, com objetivo de suprir uma possível deficiência de enxofre verificada na cultura.

A cultivar utilizada foi o H 358 da Dekalb, sendo colocadas oito sementes, por metro de fileira. Posteriormente, realizou-se desbaste deixando-se 5-6 plantas por metro de fileira, em uma população final equivalente a 62.500 plantas ha-1.

O sistema de irrigação foi do tipo localizado por gotejamento, cujas mangueiras gotejadoras possuíam espessura de $200 \mathrm{~m}$ e espaçamento de $30 \mathrm{~cm}$ entre emissores. Foi instalada uma mangueira gotejadora para linha da cultura. O manejo da irrigação foi conduzido de acordo 
com os dados de evaporação do tanque "Classe A" e com o Kc da cultura em cada fase de desenvolvimento da mesma.

A colheita foi realizada manualmente, com o corte dos capítulos no dia 25/08/2005, 115 dias após a emergência (DAE).

Foram avaliadas as seguintes variáveis: a) número de folhas por planta aos 30 e 45 DAE; b) altura de plantas aos 30 e 45 DAE (medida do nível do solo até a altura da inserção do capítulo); c) diâmetro do caule à altura de 3,0 cm do solo; d) diâmetro do capítulo; e) massa de 100 aquênios (duas amostras de 100 aquênios por parcela, secas em estufa de circulação forçada de ar por um tempo de 24 horas à temperatura de $102{ }^{\circ} \mathrm{C}$, e posteriormente pesadas); f) número de aquênios por capítulo e g) produtividade de aquênios (foram colhidos os aquênios contidos em duas linhas de 2,0 $\mathrm{m}$ na área útil de cada parcela, sendo os valores corrigidos a $0,110 \mathrm{~kg} \mathrm{~kg}^{-1}$, e expressos em $\mathrm{kg} \mathrm{ha}^{-1}$ ).

Os dados foram submetidos à análise de variância. Nas médias foi aplicada a análise de regressão (GOMES, 2000). As análises foram realizadas pelo programa computacional Sistema para Análise de Variância - SISVAR. As doses mais econômicas para cada variável analisada foram calculadas com base na derivada da equação de regressão da própria Figura de cada equação (FERREIRA, 2000).

\section{RESULTADOS E DISCUSSÃO}

Os tratamentos testados apresentaram efeitos significativos pelo teste $\mathrm{F}(\mathrm{P}<0,05)$ nas variáveis peso de 100 aquênios, diâmetro do caule, diâmetro do capítulo, número de aquênios por capítulo, altura de planta aos 30 DAE, altura de planta aos 45 DAE, número de folhas aos 30 DAE, número de folhas aos 45 DAE e produtividade. Os tratamentos com nitrogênio não alteraram o ciclo de desenvolvimento da cultura, no entanto, houve alterações em todas as características estudadas.
Para a altura de plantas, a análise de variância indicou efeito significativo aos 30 e 45 DAE (Tabela 1).

Pela Figura 1, observa-se que houve uma resposta quadrática em função da aplicação de nitrogênio para a altura aos 30 DAE, onde se obteve $40,6 \mathrm{~cm}$ na dose máxima estimada de $69 \mathrm{~kg} \mathrm{ha}^{-1}$ de N. Aos 45 DAE, obteve-se a altura de $114,7 \mathrm{~cm}$ para a quantidade de $72,9 \mathrm{~kg} \mathrm{ha}^{-1} \mathrm{de} \mathrm{N}$. Nesse último verificou-se que o nutriente aplicado em cobertura foi importante para o crescimento das plantas, fazendo com que as mesmas tivessem um bom porte, não havendo acamamento e facilitando o manejo e a colheita devido à boa altura.

Com relação ao número de folhas aos 30 e 45 DAE (Figura 2), nota-se que houve um efeito significativo da aplicação de nitrogênio em cobertura. Para os 30 DAE verificou-se uma resposta quadrática das doses de $\mathrm{N}$ aplicado em cobertura com a maior dose $\left(80 \mathrm{~kg} \mathrm{ha}^{-1}\right)$, aumentando o número de folhas até 15,5 folhas por planta. Aos 45 DAE também houve efeito significativo, verificando-se uma resposta quadrática da doses de $\mathrm{N}$ com a maior dose estudada $\left(80 \mathrm{~kg} \mathrm{ha}^{-1}\right)$, obtendo-se 29,2 folhas por planta. Isso indica que o número de folhas por planta foi influenciado pelo nitrogênio aplicado em cobertura, acompanhando o crescimento da planta, com emissão de folhas até a planta atingir seu crescimento máximo.

Quanto ao diâmetro do capítulo, a análise da variância indicou efeito significativo das doses de $\mathrm{N}$ em cobertura (Tabela 2). Nota-se que a aplicação de nitrogênio em cobertura resultou em um efeito quadrático, com o aumento do diâmetro do capítulo até a dose máxima estimada de 44,9 $\mathrm{kg} \mathrm{ha}^{-1}$ de nitrogênio, chegando a um diâmetro máximo do capítulo de 11,9 cm (Figura 3). Isso significa que a adubação nitrogenada é muito importante para o girassol, porém, não é necessária uma alta quantidade de nitrogênio para proporcionar bom crescimento do diâmetro do capítulo.

Tabela 1 - Análise de variância dos dados referentes à altura de planta e número de folhas por planta aos 30 e $45 \mathrm{DAE}$, em função de doses de nitrogênio. Cassilândia-MS, 2006.

\begin{tabular}{lccccc}
\hline \multirow{2}{*}{$\begin{array}{c}\text { Fontes de } \\
\text { variação }\end{array}$} & GL & \multicolumn{4}{c}{ Quadrado Médio } \\
\cline { 3 - 6 } & & & \multicolumn{2}{c}{ Altura de planta } & Número de folhas por planta \\
\hline Doses de N & 3 & $40,385717 * *$ & $513,632373 * *$ & $2,784342^{*}$ & $3,533317 * *$ \\
Bloco & 3 & 2,613317 & 4,939873 & 0,253225 & 0,170717 \\
Resíduo & 9 & 3,589844 & 19,492651 & 0,621453 & 1,194956 \\
\hline CV $(\%)$ & & 5,00 & 4,30 & 5,56 & 4,02 \\
\hline
\end{tabular}

** Significativo a $1 \%$ de probabilidade pelo teste F.; * Significativo a $5 \%$ de probabilidade pelo teste $\mathrm{F}$. 


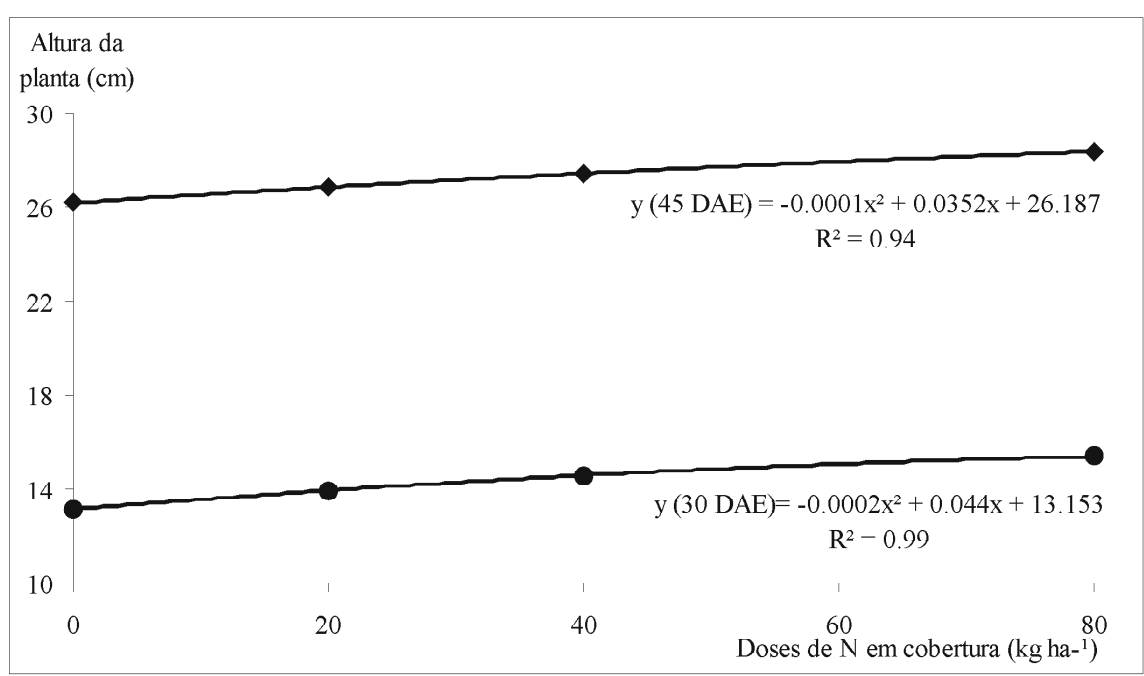

Figura 1 - Altura de planta de girassol aos 30 e 45 DAE, em função das doses de nitrogênio. Cassilândia-MS, 2006.

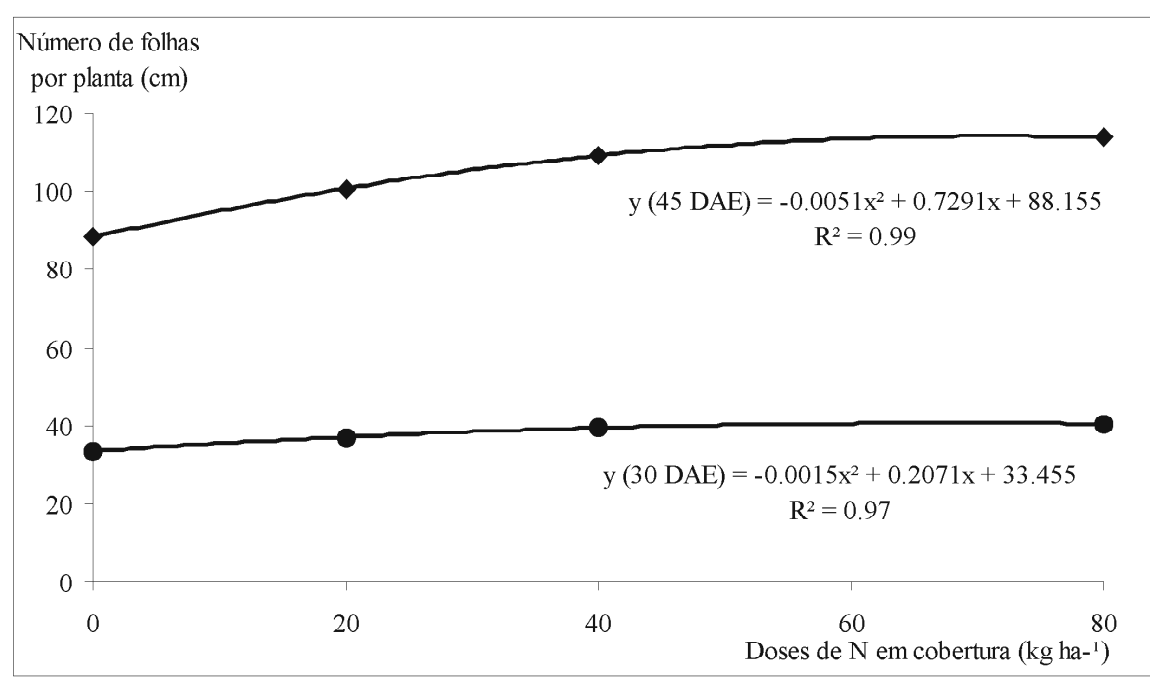

Figura 2-Número de folhas por planta de girassol aos 30 e 45 DAE, em função das doses de nitrogênio. Cassilândia-MS, 2006.

Tabela 2 - Análise de variância dos dados referentes ao diâmetro do caule, diâmetro do capítulo, número de aquênios por capítulo, massa de 100 aquênios e produtividade de grãos de girassol em função de doses de nitrogênio. Cassilândia-MS, 2006.

\begin{tabular}{lcccccc}
\hline \multicolumn{1}{c}{$\begin{array}{c}\text { Fontes de } \\
\text { variação }\end{array}$} & GL & \multicolumn{5}{c}{ Quadrado médio } \\
\cline { 3 - 7 } & & $\begin{array}{c}\text { Diâmetro do } \\
\text { caule }\end{array}$ & $\begin{array}{c}\text { Diâmetro do } \\
\text { capítulo }\end{array}$ & $\begin{array}{c}\mathrm{N}^{\mathrm{o}} \text { de aquênios } \\
\text { por capítulo }\end{array}$ & $\begin{array}{c}\text { Massa de 100 } \\
\text { aquênios }\end{array}$ & Produtividade \\
\hline Doses de N & 3 & $2,403005^{*}$ & $3,090373^{*}$ & $63209,2292^{*}$ & $0,749092^{*}$ & $3663,012323^{*}$ \\
Repetição & 3 & 0,527140 & 0,968190 & 1759,229167 & 270,750000 & 225454,80154 \\
Resíduo & 9 & 0,481769 & 0,821795 & 3969,729162 & 0,121286 & 70437,720395 \\
\hline CV $(\%)$ & & 3,90 & 8,20 & 8,20 & 10,90 & 14,73 \\
\hline
\end{tabular}

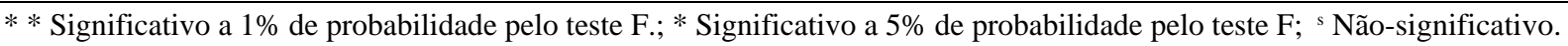




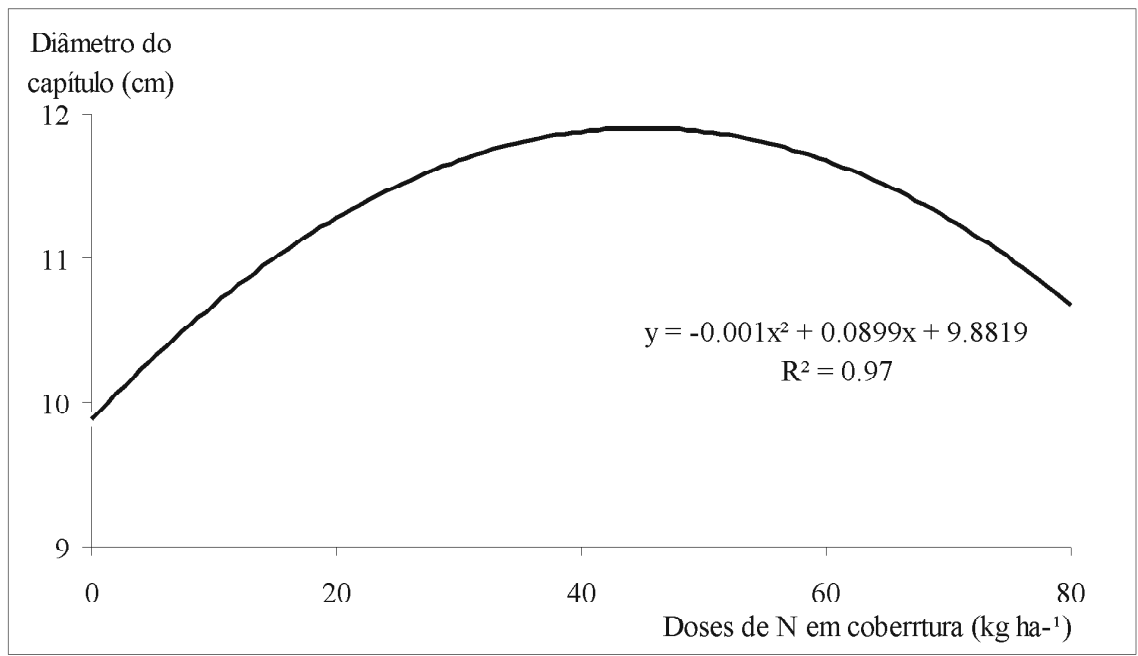

Figura 3 - Diâmetro do capítulo em função das doses de nitrogênio. Cassilândia-MS, 2006.

Com relação ao diâmetro do caule (Figura 4) observou-se, através dos resultados obtidos, um efeito quadrático com o aumento do diâmetro do caule até a dose máxima estimada de $47,8 \mathrm{~kg} \mathrm{ha}^{-1}$ de $\mathrm{N}$, chegando a um crescimento médio do caule de $18,4 \mathrm{~mm}$. O diâmetro do caule é uma característica muito importante no girassol, pois permite que ocorra menos acamamento da cultura $\mathrm{e}$ facilita seu manejo, tratos e colheita.

Estes resultados, observados na Figura 4, estão de acordo com os obtidos por Castro et al. (1999), que trabalhando com doses e métodos de aplicação de nitrogênio, verificaram que o diâmetro do caule aumentou conforme o método de aplicação de nitrogênio. Os pesquisadores observaram um melhor resultado quando se aplicou $\mathrm{N}$ em "incorporação com aiveca" obtendo-se em média 25,0 $\mathrm{mm}$ de caule.

Com relação à massa de 100 aquênios observa-se que houve um efeito positivo em decorrência da aplicação de nitrogênio em cobertura. Na Figura 5, nota-se que houve uma resposta quadrática, o que resultou no aumento do peso médio de aquênios até a dose máxima estimada de $44,9 \mathrm{Kg} \mathrm{ha}^{-1}$ de $\mathrm{N}$, sendo que o peso máximo alcançado foi de $7,19 \mathrm{~g}$ para a massa de 100 aquênios, o que refletiu no rendimento. $\mathrm{O}$ peso de aquênio é o resultado da capacidade da planta de suprir nutrientes até o limite potencial estabelecido para cada cultivar. Em geral, há uma grande diversidade de respostas especialmente associadas ao número de aquênios previamente fixados (ZAGONEL \& MUNDSTOCK, 1991).

Com relação ao número médio de aquênios por capítulo (Figura 6), observa-se um efeito quadrático da aplicação de nitrogênio em cobertura, onde obteve-se, em média, a maior quantidade de aquênios num total de 707 , para uma dose máxima de estimada de $52,6 \mathrm{~kg} \mathrm{ha}^{-1}$ de nitrogênio. Isso, provavelmente, foi influenciado pela maior disponibilidade do nutriente, sendo então um reflexo do diâmetro do capítulo. Verificou-se, neste trabalho, uma semelhança entre o número médio de aquênios por capítulo e a produtividade, que ocorreram em dosagens semelhantes. Esse resultado é semelhante ao encontrado por Carvalho \& Pissaia (2002) que obtiveram 499 aquênios por capítulo numa dosagem de $50 \mathrm{~kg} \mathrm{ha}^{-1} \mathrm{de} \mathrm{N}$ aplicado em cobertura sob plantio direto na palha, utilizando o híbrido $\mathrm{M}$ 734. Porém, os autores afirmam que obtiveram essa quantidade baixa de aquênios por capítulo, provavelmente, pela influência da disponibilidade hídrica irregular e insuficiente durante a fase de florescimento, em seu experimento no município de Palmeira/PR, no ano de 1998/99.

Quanto à produtividade de aquênios, verificou-se que houve efeito da aplicação de nitrogênio em cobertura. Na Figura 7, observa-se um efeito quadrático com aumento da produtividade até a dose máxima estimada de $51,7 \mathrm{~kg}$ $\mathrm{ha}^{-1}$ de nitrogênio, com uma produtividade de $2.101 \mathrm{~kg} \mathrm{ha}^{-1}$ de aquênios.

Sharma \& Gaur (1998), trabalhando com métodos de aplicação e as doses de $\mathrm{N}$ variando entre 0 e $90 \mathrm{~kg} \mathrm{ha}^{-1}$, em girassol, encontraram respostas significativas até a dose máxima estudada de $\mathrm{N}$; quanto aos métodos de aplicação do fertilizante, os autores constataram que os aumentos na produção de grãos, devido à incorporação em sulco de $5,0 \mathrm{~cm}$ de profundidade abaixo da semente, foi $9 \%$ e $11 \%$ maior em relação ao método de aplicação a lanço, antes da aração ou antes da semeadura, respectivamente. 


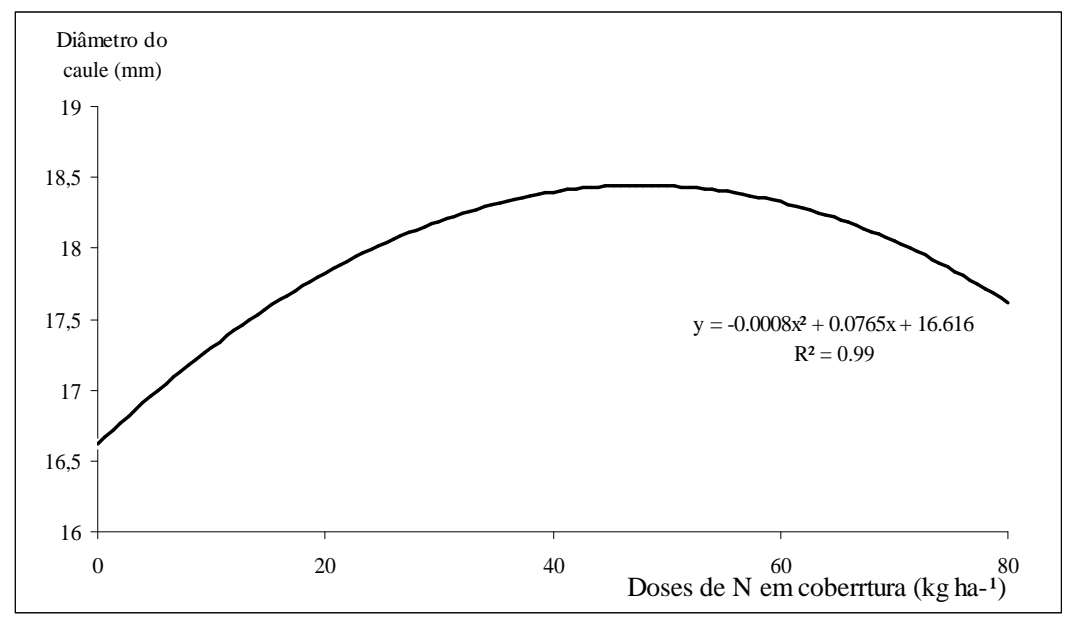

Figura 4 - Diâmetro do caule em função das doses de nitrogênio. Cassilândia-MS, 2006.

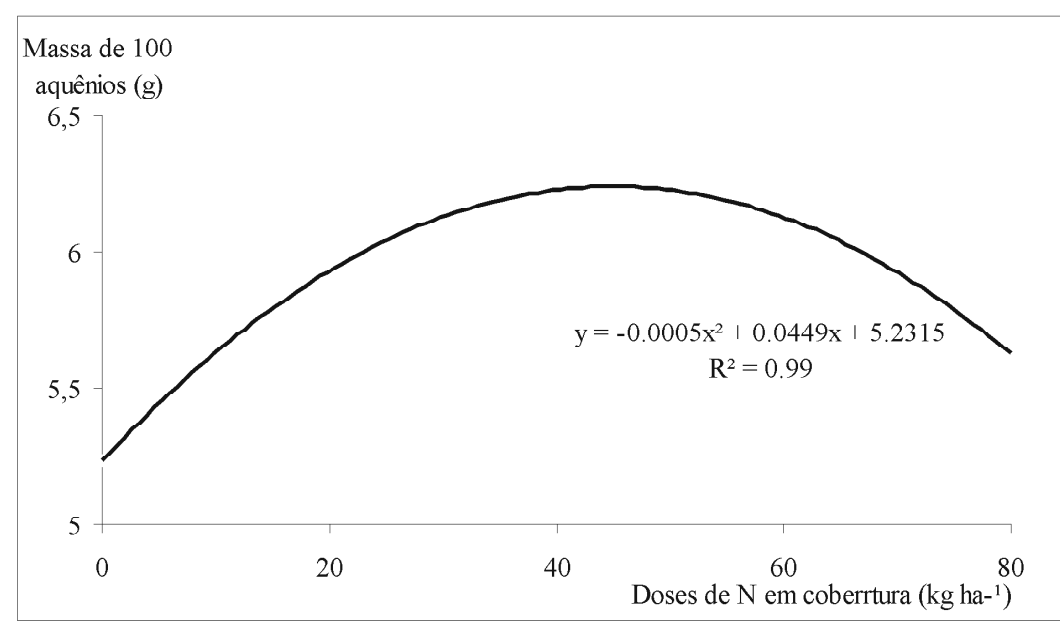

Figura 5 - Massa de 100 aquênios em função das doses de nitrogênio. Cassilândia-MS, 2006.

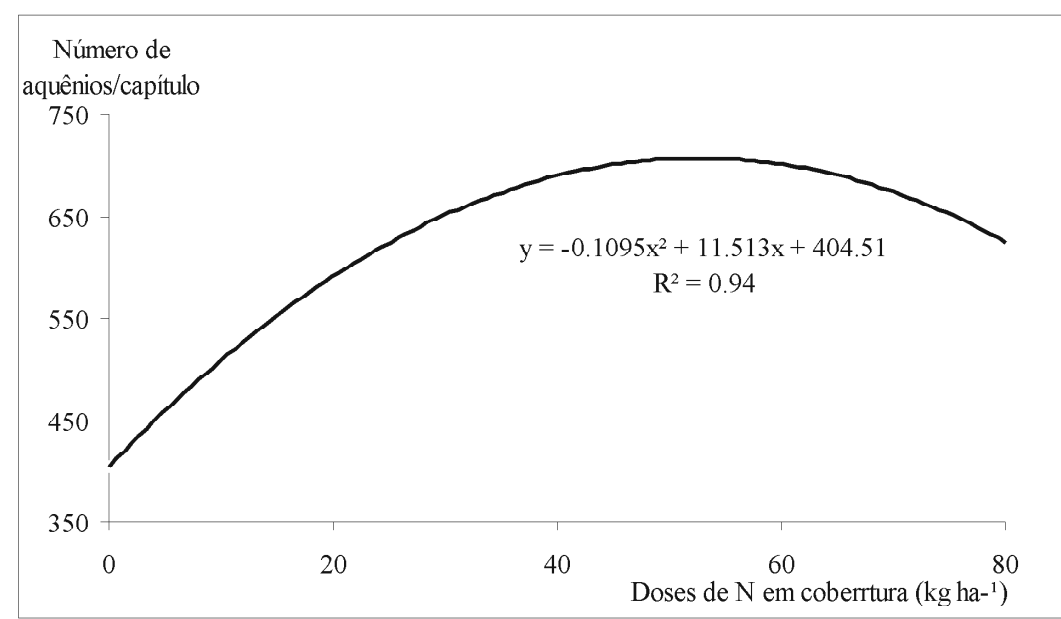

Figura 6-Número de aquênios por capítulo em função das doses de nitrogênio. Cassilândia-MS, 2006. 


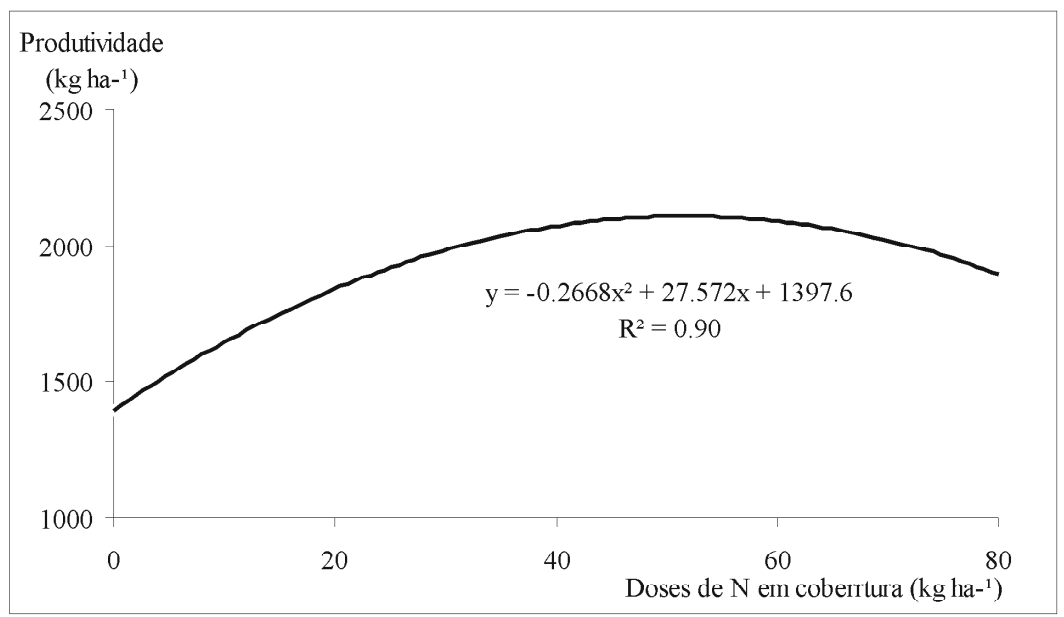

Figura 7 - Produtividade de aquênios em função das doses de nitrogênio. Cassilândia-MS, 2006.

Constataram-se que os resultados encontrados neste experimento estão de acordo com os resultados obtidos por outros autores, provando que a adubação nitrogenada em cobertura na cultura do girassol proporcionou um acréscimo na produção, em comparação ao tratamento sem $\mathrm{N}$ (testemunha), tornando-se assim uma prática viável, trazendo retorno ao produtor se bem aplicada e na época certa.

\section{CONCLUSÕES}

A adubação nitrogenada em cobertura proporcionou um aumento em todas as características estudadas, sendo que a dose de $\mathrm{N}$, de máxima eficiência técnica indicada para se ter uma boa produtividade é de 55 $\mathrm{kg} \mathrm{ha}^{-1}$ de $\mathrm{N}$ para o cultivo do girassol na região de Cassilândia-MS.

\section{REFERÊNCIAS BIBLIOGRÁFICAS}

CARVALHO, D. B.; PISSAIA, A. Cobertura nitrogenada em girassol sob plantio direto na palha. Scientia Agrária, Piracicaba, v. 1/2, p. 41-45, 2002.

CASTRO, C. de; BALLA, A.; CASTIGLIONI, V. B. R. Doses e métodos de aplicação de nitrogênio em girassol. Scientia Agrícola, Piracicaba, v. 56, n. 4, p. 827-833, 1999.

EMPRESA BRASILEIRA DE PESQUISA AGROPECUÁRIA. Centro Nacional de Pesquisa de Solos. Sistema brasileiro de classificação de solos. Brasília, DF, 1999. $412 \mathrm{p}$.

FERREIRA, D. F. Análise estatística por meio do SISVAR (Sistema para Análise de Variância) para Windows versão
4.0. In: REUNIÃO ANUAL DA REGIÃO BRASILEIRA DA SOCIEDADE INTERNACIONAL DE BIOMETRIA, 45. 2000, São Carlos. Anais... São Carlos: UFSCar, 2000. p. 255258.

FLECK, N. G.; SILVA, P. R. F. da. Efeitos da época de aplicação de nitrogênio em cobertura na cultura do girassol, com e sem controle de plantas daninhas. Pesquisa Agropecuária Brasileira, Brasília, v. 24, n. 6, p. 669-676, 1989.

GOMES, F. P. Curso de estatística experimental. 14. ed. Piracicaba: ESALQ/USP, 2000. 477 p.

LOZANOVIC, M.; STANOJEVIC, D. Effect of increasing nitrogen doses on important sunflower quantitative, biological, and morphological traits of sunflower. In: INTERNATIONAL SUNFLOWER CONFERENCE, 12., 1988, Novi Sad. Proceedings... Novi Sadi: [s.n.], 1988. v. 1, p. 274-275.

SAMENI, A. M.; MAFTOUN, M.; HOJJATTI, S. M.; SHEIBANY, B. Effect of fertlizer-N and herbicides on the growth and N content of sunflower. Agronomy Journal, Madison, v. 68, p. 285-288, 1976.

SFREDO, G. J.; CAMPO, R. J.; SARRUGE, J. R. Girassol: nutrição mineral e adubação. Londrina: Embrapa-CNPSo, 1984. 36 p. (Circular técnica, 8).

SHARMA, S. K.; GAUR, B. L. Effect of level and methods of nitrogen application on seed yield and quality of sunflower. Indian Journal Agronomy, New Delhi, v. 33, p. 330-331, 1988. 
SMIDERLE, O. J. Orientações gerais para o cultivo do girassol em Roraima. Boa Vista: Embrapa Roraima, 2000. (Embrapa informa, 8).

SMIDERLE, O. J. O girassol como alternativa de combustível. _ Disponível _ em: <http:// iwww.agrisustentavel.com/artigos ${ }^{\prime}$ Acesso em: 18 out. 2004 .
STEER, B. T.; HOCKING, P. J. Leaf and floret production in sunflower (Helianthus annus L.) as affected by nitrogen supply. Annals of Botany, Oxford, v. 52, p. 267-277, 1983.

ZAGONEL, J.; MUNDSTOCK, C. M. Doses e épocas de aplicação de nitrogênio em cobertura em duas cultivares de girassol. Pesquisa Agropecuária Brasileira, Brasília, v. 26, p. 1487-1492, 1991. 